\title{
CORRELATION OF ECHO CARDIAC CALCIFICATION SCORE WITH CORONARY CALCIUM SCORE AT MULTI-DETECTOR COMPUTED TOMOGRAPHY
}

\author{
By
Fatma Mohamed Mohamed Ahmed, Islam Shawky Abd El-Aziz and Wael Mohamed Attia

Department of Cardiology, Faculty of Medicine, Al-Azhar University (Cairo)

Corresponding author: Fatma Mohamed Mohamed Ahmed,

Mobile: 01025972449, E-mail: zahraa2241990@ gmail.com

\begin{abstract}
Background: Echocardiography-derived calcium score (ECS) was able to predict the presence of extensive coronary calcium and obstructive Coronary artery disease(CAD), assessed using Multi slice CT (MSCT) coronary angiography. Furthermore, significant linear trends were observed between ECS and extent and severity of coronary atherosclerosis and number of calcified coronary artery lesions.
\end{abstract}

Objective: To correlate an echocardiography-derived calcium score (ECS), obtained using coronary artery calcium Score (CACS) and the presence of obstructive CAD.

Patients and Methods: The study comprised 100 patients (males and females) presented with symptoms suspected of stable CAD. All cases were recruited from the outpatient clinic in Agouza police Hospital in Cairo and Islamic center of Al-Azhar University during a period of fourteen months from 1/11/2018 to 30/12/2019.

Results: Linear regression analysis identified that the most independent variables that can predict AVC were CAC score, dyslipidemia, and the most independent variable that can predict obstructive coronary artery disease was the presence of coronary artery calcification and higher CAC score. ROC curve analysis was used to test the predictive value of aortic valve calcification (AVC), Mitral annulus calcification (MAC) and CAC scores for the presence or absence of obstructive CAD. This analysis showed that AVC and MAC scores were inferior to $\mathrm{CAC}$ score which was found to have the highest predictive value evidenced by an area under the curve of 0.763 (95\%CI: 0.781, 0.913). MAC score was inferior to AVC score which was found to have the highest predictive value evidenced by an area under the curve of 0.815 (95\% CI: $0.758,0.879)$.

Conclusion: The echocardiographic calcium scores specifically the MVC and AVC was correlated to be CAC. ECS can predict the CAC score. ECS can predict the presence or absence CAD.

Keywords: Multi-detector computed tomography, coronary artery calcium score.

\section{INTRODUCTION}

In the last 2 decades, the clinical relevance of vascular calcific deposits has emerged. The amount of calcium in both coronary arteries and the aorta correlates with atherosclerotic plaque burden in each vascular bed (Thompson and Towler, 2012) and is associated with increased risk of cardiovascular events (SalmoiragoBlotcher et al., 2011). Severe coronary calcific deposits are associated with the presence of myocardial ischemia, and 
extent of calcium in the aorta is related to coronary, carotid, and peripheral artery disease (Tousoulis et al., 2012).

Mitral annular calcium and aortic valve sclerosis appears to be the result of similar pathologic processes. Both are not simple passive degenerative disorders influenced by mechanical stress, but active inflammatory processes with histopathologic features similar to atherosclerosis (Rajamannan et al., 2011). Previous clinical studies have shown significant associations between mitral annular calcium and aortic valve sclerosis with cardiovascular risk factors, (Linefsky et al., 2011) impaired coronary microvascular function, (Marciano et al., 2012) subclinical systemic calcified atherosclerosis, (Al Rifai et al., 2015) inducible myocardial ischemia, (Panza et al., 2013) and obstructive CAD at conventional coronary angiography (Abdulla et al., 2011).

Large population cohort studies showed that aortic valve sclerosis and mitral annular calcium are associated with increased cardiovascular morbidity and mortality (Thanassoulis et al., 2013). Because it is unlikely that aortic valve sclerosis and mitral annular calcium directly lead to adverse cardiovascular outcomes, their relation with coronary atherosclerosis most likely explains these observations. Calcific deposits of the papillary muscles are less commonly observed in the general population and usually limited to their apical portion. Similarly to mitral annular calcium and aortic valve sclerosis, papillary muscle calcium is associated with the presence of CAD despite potentially different underlining mechanisms, (Weiss et al.,
2013) more likely a consequence of necrosis or fibrosis caused by narrowing of the coronary arterial lumen by atherosclerosis (Yahagi et al., 2016).

Noninvasive modalities for the diagnosis of CAD are important for both screening of asymptomatic subjects and risk stratification of symptomatic patients to identify those who could benefit from invasive coronary angiography. Recently, MSCT coronary angiography has emerged as a feasible and accurate technique allowing detection of coronary atherosclerosis by assessing the coronary artery calcium burden and performing noninvasive angiography. However, it is expensive and not widely available. Moreover, it still carries high radiation exposure, which limits its widespread use in asymptomatic patients, and a potential associated risk of allergic reactions and nephrotoxicity related to the use of iodinated contrast agents (Youssef, et al., 2013).

A semi-quantitative calcium score was devised to assess overall (non-coronary) cardiac calcification. This score proved easy to apply to clinically indicated echocardiograms of varying technical quality. When compared with $\mathrm{CT}$ as a gold standard, the new score performed reasonably well. Importantly the echo score, when dichotomized at a value of 5 or greater, can serve as a marker of severe coronary disease. From a practical standpoint the simplified version (dichotomized at a value of 3 or greater) performed equally well in predicting high CAC scores. It is easily applied in routine clinical practice and can alert the ordering physician to the likely presence of a high burden of coronary atherosclerosis. This 


\section{CORRELATION OF ECHO CARDIAC CALCIFICATION SCORE WITH...}

potentially increases the prognostic information provided by echocardiography (Pressman et al., 2011).

The present work aimed to correlate echocardio calcium cation score with coronary calcium score at multi-detection competed tomography.

\section{PATIENTS AND METHODS}

The study comprised 100 patients were recruited from the outpatient clinic in Agouza police Hospital in Cairo and Islamic center of Al-Azhar University during a period from 1/11/2018 to $30 / 12 / 2019$ divided into two groups Patient with obstructive $\mathrm{CAD}=44$ patients and Patient with Non obstructive $\mathrm{CAD}=56$ patients who presented with symptoms of intermediate likelihood stable CAD and indicated for coronary CT angiography according to ESC guideline.

Patients with aortic valve stenosis, rheumatic valvular disease, prosthetic valves, a history of MI, PCI, CABG, cardiomyopathy, rhythm other than sinus rhythm, contraindications for multi-slice computed tomography or poor transthoracic acoustic were excluded.

All patients underwent informed consent, history taking of risk factors of CAD as hypertension, diabetes, dyslipidemia and smoking. Full clinical examination included blood pressure, fasting blood sugar, heart rate. Laboratory investigations included fasting blood sugar, serum glycated hemoglobin (HbA1c), lipid profile including high density lipoprotein (HDL), low density lipoprotein (LDL), total cholesterol (TC) and triglycerides (TG), and serum creatinine.
Transthoracic echocardiography was performed in all patients within 1 month of MSCT coronary angiography All selected patients underwent a standard rest transthoracic echocardiography using vivid E9 and Philips ie33 system equipped with S5 probe, aortic valve sclerosis was defined as focal areas of increased echogenicity and thickening of the aortic valve leaflets with velocity $2.5 \mathrm{~m} / \mathrm{s}$ across the aortic valve. Each aortic valve leaflet was graded on a scale of 0 (normal) to 3 (severe) according to leaflet thickening and calcific deposits. The highest score for a given cusp was assigned as the overall degree of aortic valve sclerosis. Mitral annular calcium was defined as an intense and bright echo-producing structure located at the junction of the atrioventricular groove and posterior mitral valve leaflet and was measured from the leading anterior to the trailing posterior edge and judged on a scale of 0 (normal) to 3 (severe). Papillary muscle calcium was defined as a bright echo involving the head of 1 or both papillary muscles. Ascending aorta calcium was defined as a focal or diffuse area of increased echo reflectance and thickening in the aortic root on the parasternal longaxis view

MSCT coronary angiography was performed using a 64-slice MSCT scanner (Aquilion 64; Toshiba Medical Systems, Tokyo, Japan). Heart rate and blood pressure were monitored before the examination in each patient. In the absence of contraindications, patients with a heart rate 65 beats/min were administered oral blockers (Atenolol 50 or $100 \mathrm{mg}$, single dose, 1 hour before the examination). First, a prospective coronary calcium scan without contrast 
enhancement was performed, followed by MSCT coronary angiography performed according to the protocol described elsewhere (Schuijf et al., 2006).

Data were subsequently transferred to dedicated workstations for post processing and evaluation (Advantage; GE Healthcare, Milwaukee, Wisconsin, and Vitrea 2; Vital Images, Minnetonka, Minnesota). MSCT data analysis was performed by 2 experienced observers who had no knowledge of the patient's medical history and symptom status. Disagreement was solved by consensus or evaluation by a third observer. Coronary artery calcium was identified as a dense area in the coronary artery 130 Hounsfield units. A total CACS was recorded for each patient. According to the total CACS, patients were subsequently categorized as having no calcium (total score 0 ) or low (total score 1 to 100), moderate (total score 101 to 400 ), and severe (total score 400) coronary artery calcium (Agatston et al., 1990).

MSCT coronary angiograms were evaluated for the presence of CAD on patient, vessel, and segment levels. For this purpose, both the original axial data set and curved multiplanar reconstructions were used. Coronary arteries were divided into 17 segments according to the modified American Heart Association classification (Austen et al., 1975).

Each segment was evaluated for the presence of atherosclerotic plaque, and 1 coronary plaque was assigned per coronary segment. Subsequently, type of plaque was determined as (1) non calcified plaques, plaques with a lower density compared with the contrastenhanced vessel lumen; (2) calcified plaques, plaques with high density; and (3) mixed plaques, plaques with noncalcified and calcified elements within a single plaque. Finally, plaques were classified as obstructive (50\% luminal narrowing) or non-obstructive.

\section{Statistical analysis of data:}

Data were entered on the computer using "Microsoft Office Excel Software" program (2010) for windows, then transferred to the Statistical Package for Social Sciences Software program, version 21 (SPSS) to be statistically analyzed. Quantitative data were statistically described in terms of mean \pm standard deviation ( \pm SD), while qualitative data were statistically described in terms of frequencies (number of cases) and percentages when appropriate. Student T-Test: was used for independent samples for Comparison between two groups with quantitative data and normally distributed. Chi-Square test: was used for Comparison between groups with qualitative data.

Receiver operator characteristic (ROC) analysis was created to determine the sensitivity and specificity of the CCS scores for obstructive and Severe CAD as a function of the minimum score required defining a positive study. We added AVC and MAC calcification to the model to demonstrate the incremental values of these. The area under each curve represented the ability to detect patients with obstructive angiographic disease. $\mathrm{P} \leq$ 0.05 was considered statistically significant. 


\section{CORRELATION OF ECHO CARDIAC CALCIFICATION SCORE WITH...}

\section{RESULTS}

$54 \%$ population had HTN, $62 \%$ had DM, 59\% had dyslipidemia and $46 \%$ of them were smoker. Regarding chest pain
$81 \%$ of them had typical chest pain, and $19 \%$ of them had a typical chest pain (Table 1).

Table (1): Clinical characteristics of studied group

\begin{tabular}{|l|c|}
\hline Patient baseline characteristics & Number (\%) \\
\hline Hypertension & $54(54 \%)$ \\
\hline HR & $66.1 \pm 4.2$ \\
\hline DM & $\mathbf{6 2}(62 \%)$ \\
\hline Dyslipidemia & $59(59 \%)$ \\
\hline Smoker & $46(46 \%)$ \\
\hline Chest pain & \\
$\bullet \quad$ Typical & $\mathbf{8 1}(81 \%)$ \\
$\bullet \quad$ Atypical & $19(19 \%)$ \\
\hline
\end{tabular}

Distribution of coronary artery calcium score among total studies people $54 \%$ had CAC score of (0-10) $36 \%$ had CAC score of (11-100) $10 \%$ had CAC score(101-
400), and no patients had CAC score $>400$, Mean CAC scores of studied patients was 39.3 \pm 73.1 (Table 2).

Table (2): Calcium scoring distribution among the studied patients

\begin{tabular}{|c|c|c|}
\hline Calcium Scoring & Total $(\mathrm{N}=100)$ & Mean \pm SD \\
\hline Calcium score (0-10) & $54(54 \%)$ & \multirow{8}{*}{$39.3 \pm 73.1$} \\
\hline Calcium score (11-100) & $36(36 \%)$ & \\
\hline Calcium score (101-400) & $10(10 \%)$ & \\
\hline Calcium score (>400) & $0(0 \%)$ & \\
\hline Range & $0-392$ & \\
\hline Degree of CAD & Number (\%) & \\
\hline Non obstructive CAD & $56(56 \%)$ & \\
\hline obstructive CAD & $44(44 \%)$ & \\
\hline
\end{tabular}

Distribution of atherosclerotic coronary arterial localization among total studies population showed that 23 patients (52.3\%) had LAD obstruction, while 21 patients $(47.7 \%)$ had LCX obstruction,9 patients $(20.5 \%)$ had RCA obstruction, and 8 patients $(18.2 \%)$ had LMT obstruction. Thirty patients $(53.6 \%)$ had LAD non obstruction, while 28 patients (50\%) had LCX non obstruction. Ten patients (17.9\%) had RCA non obstruction, while 7 patients $(12.5 \%)$ had LMT non obstruction (Table 3).

Table (3): Distribution of atherosclerotic CAD

\begin{tabular}{|l|c|c|}
\hline Parameters & $\begin{array}{c}\text { Non- Obstruction } \\
\mathbf{N}(\mathbf{5 6})(\boldsymbol{\%})\end{array}$ & $\begin{array}{c}\text { Obstruction } \\
\mathbf{N}(\mathbf{4 4})(\boldsymbol{\%})\end{array}$ \\
\hline LAD & $30(53.6 \%)$ & $23(52.3 \%)$ \\
\hline LCX & $28(50 \%)$ & $21(47.7 \%)$ \\
\hline RCA & $10(17.9 \%)$ & $9(20.5 \%)$ \\
\hline LMT & $7(12.5 \%)$ & $8(18.2 \%)$ \\
\hline
\end{tabular}


Semi quantitative score of cardiac calcification on the total studies population showed that no patient had papillary muscle or arch calcification.
Mild MAC was present in 4 patients vs moderate MAC was present in one patient, and mild AVC was present in 26 patients (Table 4).

Table (4): Semi quantitative score of cardiac calcification on the echocardiographic examination

\begin{tabular}{|l|c|c|c|c|}
\hline Calcifications & $\begin{array}{c}\text { Papillary } \\
\text { muscle } \\
\text { calcium }\end{array}$ & $\begin{array}{c}\text { Mitral annulus } \\
\text { calcium }\end{array}$ & $\begin{array}{c}\text { Aortic valve } \\
\text { sclerosis/ } \\
\text { calcification }\end{array}$ & $\begin{array}{c}\text { Ascending } \\
\text { aorta } \\
\text { wall calcium }\end{array}$ \\
\hline - $\mathbf{0}$ & absent 100 & absent 95 & absent 74 & absent 100 \\
\hline $\mathbf{1}$ & present 0 & mild 4 & mild 26 & present 0 \\
\hline - $\mathbf{2}$ & 0 & moderate 1 & moderate 0 & 0 \\
\hline $\boldsymbol{- 3}$ & 0 & Severe 0 & Severe 0 & 0 \\
\hline
\end{tabular}

There was an insignificant difference between calcium score distribution and risk factors, i.e. DM, HTN, dyslipidemia, and smoking (Table 5).

Table (5): Relation between severity of calcium scoring and risk factors

\begin{tabular}{|c|c|c|c|c|c|c|c|c|}
\hline \multirow{3}{*}{$\begin{array}{l}\text { Risk } \\
\text { Factors }\end{array}$} & \multicolumn{6}{|c|}{ Calcium score $(0-10)(\mathrm{N}=54)$} & \multirow{2}{*}{\multicolumn{2}{|c|}{ Chi-square test }} \\
\hline & \multicolumn{2}{|c|}{ No. } & \multicolumn{2}{|c|}{$\begin{array}{c}\text { Calcium score } \\
(11-100) \\
(\mathrm{N}=36) \\
\end{array}$} & \multicolumn{2}{|c|}{$\begin{array}{c}\text { Calcium score } \\
(101-400) \\
(\mathrm{N}=10) \\
\end{array}$} & & \\
\hline & $\begin{array}{l}2 \\
3\end{array}$ & $\%$ & No. & $\%$ & No. & $\%$ & $\chi^{2}$ & P-value \\
\hline $\begin{array}{c}\text { Diabetes } \\
\text { mellitus }\end{array}$ & $\begin{array}{l}2 \\
9 \\
\end{array}$ & $42.6 \%$ & 11 & $30.6 \%$ & 4 & $40 \%$ & 2.372 & $0.668^{*}$ \\
\hline Hypertension & $\begin{array}{l}2 \\
2 \\
\end{array}$ & $53.7 \%$ & 18 & $50 \%$ & 7 & $70 \%$ & 1.264 & 0.531 \\
\hline Dyslipidemia & $\begin{array}{l}2 \\
6\end{array}$ & $40.7 \%$ & 12 & $33.3 \%$ & 7 & $70 \%$ & 2.133 & 0.545 \\
\hline Smoking & & & & & & & 0.28 & 0.869 \\
\hline
\end{tabular}

Linear regression analysis was performed in order to identify the most independent variable that can predict
CAD. The independent predictors for CAD category were MAC, AVC, HTN, smoking and CAC score (Table 6).

Table (6): Linear regression analysis to identify predictors of CAD

\begin{tabular}{|c|c|c|c|}
\hline Regression & $\mathbf{R}$ & $\mathbf{R}^{2}$ & P value \\
\hline Variables & $\mathbf{0 . 7 0 1}$ & $\mathbf{0 . 4 2 1}$ & $<\mathbf{0 . 0 0 2}$ \\
\hline AVC and/or MAC & $\mathbf{0 . 6 5 1}$ & $\mathbf{0 . 4 4 2}$ & $<\mathbf{0 . 0 0 5}$ \\
\hline HTN & $\mathbf{0 . 7 2 1}$ & $\mathbf{0 . 5 1 3}$ & $\mathbf{0 . 0 1 2}$ \\
\hline Smoking & $\mathbf{0 . 5 7 4}$ & $\mathbf{0 . 2 6 8}$ & $<\mathbf{0 . 0 0 1}$ \\
\hline CAC score &
\end{tabular}

ROC curve analysis showed that AVC and MAC scores were inferior to CAC score which was found to have the highest predictive value evidenced by an area under the curve of 0.763 (95\% CI: 0.781, 0.913) MAC score was inferior to AVC 


\section{CORRELATION OF ECHO CARDIAC CALCIFICATION SCORE WITH...}

score which was found to have the highest

under the curve of $0.815(95 \% \mathrm{CI}: 0.758$, predictive value evidenced by an area 0.879 (Table 7).

Table (7): ROC curve analysis curve for the presence or absence of any obstructive/non obstructive CAD

\begin{tabular}{|l|c|c|c|c|}
\hline \multicolumn{1}{|c|}{ Parameters } & \multirow{2}{*}{ AUC } & Sensitivity & Specificity & 95\% CI \\
\hline Analysis & 0.741 & $65 \%$ & $60 \%$ & $(0.645-0.781)$ \\
\hline MAC score & 0.581 & $45 \%$ & $43 \%$ & $(0.419-0.619)$ \\
\hline CAC score & 0.763 & $82 \%$ & $80 \%$ & $(0.814-0.913)$ \\
\hline Total echo CAC score & 0.735 & $78 \%$ & $75 \%$ & $(0.765-0.965)$ \\
\hline
\end{tabular}

\section{DISCUSSION}

Coronary artery calcifications are strongly correlated with atherosclerosis and the coronary artery calcium score (CACS) by coronary computed tomography angiography (CCTA) can be used to make better prediction regarding the individual risk of future coronary events (Silverman et al., 2013).

In our study, $54 \%$ patients had HTN, $62 \%$ patients had DM, 59\% patients had dyslipidemia and $46 \%$ patients were smokers. Regarding chest pain, 81 $\%$ patients had typical chest pain and 19\% patients had a typical chest pain. Gaibazzi et al. (2014) found that $66 \%$ were hypertensive, $55 \%$ hypercholesterolemia, $30 \%$ were active smokers and $14 \%$ diabetics.

Our study showed distribution of coronary artery calcium score among total studied population, $54 \%$ had CAC score of $0-10$, while $36 \%$ had CAC score of 11 100 , while $10 \%$ had CAC score of 101 400 , and no patient had CAC score $>400$. Mean CAC scores of studied patients was $39.3 \pm 73.1$.

According to coronary CTA result, the total population was classified into 44 patients with obstructive CAD, and $56 \%$ patients with non-obstructive CAD.
Regarding obstructive CAD, $52.3 \%$ had LAD obstruction, $47.7 \%$ had LCX obstruction, $20.5 \%$ had RCA obstruction and $18.2 \%$ had LMT obstruction. Regarding non-obstructive CAD, 53.6\% had LAD non-obstruction, while 50\% had LCX non-obstruction, while $17.9 \%$ had RCA non-obstruction and $12.5 \%$ had LMT non-obstruction. Gaibazzi et al. (2014) used a $>50 \%$ diameter stenosis to define obstructive CAD at CCTA, patients with no CAD, single-vessel, 2-vessel or 3vessel disease were $61 \%, 23 \%, 9 \%$ and $7 \%$, respectively; accordingly, $61 \%$ had no obstructive CAD, while $39 \%$ had at least one diseased (>50\% stenosis) coronary artery.

Our study showed the semi quantitative score of cardiac calcification on the total population. No patient had papillary muscle or aortic root calcification. Mild MAC was present in 4 patients versus moderate MAC in one patient. But, mild AVC was present in $26 \%$ patients. Saha et al. (2015) observed moderate or severe calcific deposit in the aortic valve in $29.3 \%$, followed by the aortic root $(23.8 \%)$, and the left main coronary artery (12.4\%) Moderate or severe calcific deposits on the mitral annulus were seen in $10.8 \%$. 
Saha et al. (2015) found that compared with participants with a composite calcium score of 0 , those with a score of $>$ 2 were older and had a higher proportion with a history of diabetes mellitus or coronary revascularization. The proportion of participants with previous myocardial infarction, heart failure, stroke, or peripheral arterial disease did not differ significantly between groups. Participants with calcific deposits at multiple sites also had higher diastolic blood pressure, reduced renal function, and higher serum phosphorus levels. However, there were no significant differences between the groups in the fasting cholesterol profiles or C-reactive protein levels at baseline. Participants with a composite calcium score of 0 had a significantly lower incidence of $\mathrm{CV}$ events than participants with composite calcium score of $>2$. Participants with a composite score of 0 also had significantly lower rates of death and myocardial infarction compared with participants with a composite score of $>2$.

In our study, ECS and CAC score were significantly correlated. Nucifora et al. (2011) confirmed the relation between eCS, CAC and CAD, but found that the best predictive cutoff was eCS $>2$. This confirms the presence of a grey zone, as in most scores in medicine, between eCS 1 and 2, in which results should be interpreted with clinical caution.

Koulaouzidis et al. (2013) showed that the presence of cardiac calcium outside the coronary tree may not only reflect coronary calcium burden but also the vulnerability of atherosclerotic plaques, acting like a feature of additional risk for cardiac events, independently from the presence or grade of a coronary stenosis. This would explain the robust link between cardiac calcium and prognosis, in spite of a weaker correlation with coronary artery stenosis grade. Criqui et al. (2014) linked coronary plaque vulnerability to calcium density in the plaque, by so doing demonstrating that the total burden of coronary calcium is only part of the cardiac risk picture.

Gaibazzi et al. (2014) showed also a significant positive correlation. When eCS was correlated with the number of diseased vessels at CCTA, there was a weak to low correlation only when the most severe definition of CAD (diameter stenosis $>70 \%$ ) was applied. CACS correlated with the number of diseased vessels also (and more robustly than $>70 \%$ ) when the definition of milder disease, i.e. stenosis $>50 \%$, was used. Only 12 patients had at least one $>70 \%$ stenosis.

Linear regression analysis was performed in order to identify the most independent variable that can predict CAD. We found that the independent predictors for CAD category were MAC\&AVC, HTN, FH of IHD, and smoking.

Gaibazzi et al. (2014) demonstrated that global chi square of logistic regression models significantly increased when adding eCS to age and clinical variables and further when finally adding CACS score. Saha et al. (2015) indicated that the following variables were significantly associated with the composite cardiac calcium score: age, history of diabetes mellitus, previous coronary revascularization, diastolic blood 
pressure, estimated glomerular filtration rate, and serum phosphorus level.

ROC curve analysis was used to test the predictive value of AVC, MAC and CAC scores for the presence or absence of obstructive CAD. This analysis showed that AVC and MAC scores were inferior to CAC score which was found to have the highest predictive value evidenced by an area under the curve of 0.763 (95\%CI: $0.781,0.913)$.

We also used ROC curve analysis to test the predictive value of AVC and MAC scores for the presence or absence of CAC. This analysis showed that MAC score was inferior to AVC score which was found to have the highest predictive value evidenced by an area under the curve of 0.815 (95\%CI: $0.758,0.879$ ).

Corciu et al. (2010) estimated the correlation between the total heart calcification score index (CSI), assessed by echocardiography, left ventricle mass index (LVMI), Framingham risk score (FRS), and angiographic ally assessed coronary artery disease (CAD). They concluded that calcification score index calculated as the sum of aortic root sclerosis, aortic valve sclerosis, and mitral annulus calcification, is associated with risk factor profile, coronary atherosclerosis and left ventricle mass index. The low cost, portable, facile and radiation free nature of the ultrasound approach make CSI an attractive candidate in the ongoing search for the ideal marker of vascular and valvular calcification.

Gaibazzi et al. (2014) demonstrated that eCS or AVC+MVC had similar capability (AUC 0.77 and $\mathrm{AUC}=0.78$, respectively) to predict a high CACS score, while AVC and MVC (AUC 0.67) alone had slightly lower AUC values. Regarding the prediction of obstructive CAD, CACS had the highest predictive power when compared with eCS. They concluded that eCS, calcium score easily obtainable during standard echocardiography, is moderately to strongly correlate with nCACS by CCTA. The full eCS score correlates with nCACS better than its single components. It correlates with CACS and predicts severe coronary calcification (CACS $>400$ ), a known predictor of cardiovascular morbidity and mortality. The eCS also predicts obstructive $\mathrm{CAD}$, incrementally to age and clinical variables; although for this purpose CACS remains the most accurate score. Saha et al. (2015) concluded that a simple TTE-derived composite cardiac calcium score was independently predictive of death in patients with pre-existing CAD.

\section{CONCLUSION}

The echocardiographic calcium score specifically the MVC and AVC was correlated to be CAC. Ecs can predict the $\mathrm{CAC}$ score, and the presence or absence CAD.

\section{REFERENCES}

1. Abdulla J, Asferg $\mathrm{C}$ and Kofoed $\mathrm{KF}$ (2011): Prognostic value of absence or presence of coronary artery disease determined by 64-slice computed tomography coronary angiography a systematic review and meta-analysis. The international journal of cardiovascular imaging, 27(3): 413-420.

2. Agatston AS, Janowitz WR, Hildner FJ, Zusmer NR, Viamonte $M$ and Detrano $R$ (1990): Quantification of coronary artery calcium using ultrafast computed tomography. J Am Coll Cardiol. 15:827-832. 
3. Al Rifai M, Silverman MG, Nasir K, Budoff MJ, Blankstein R, Szklo M, Katz R, Blumenthal RS and Blaha MJ (2015): The association of nonalcoholic fatty liver disease, obesity, and metabolic syndrome, with systemic inflammation and subclinical atherosclerosis: the Multi-Ethnic Study of Atherosclerosis (MESA). Atherosclerosis, 239(2): 629-633.

4. Austen WG, Edwards JE, Frye RL, Gensini GG, Gott VL, Griffith LS, McGoon DC, Murphy ML and Roe BB (1975): A reporting system on patients evaluated for coronary artery disease. Report of the Ad Hoc Committee for Grading of Coronary Artery Disease, Council on Cardiovascular Surgery, American Heart Association. Circulation; 51:5-40.

5. Corciu AI, Siciliano V, Poggianti E, Petersen C, Venneri $L$ and Picano $E$ (2010): Cardiac calcification by transthoracic echocardiography in patients with known or suspected coronary artery disease. Int J Cardiol. 142(3):288-295.

6. Criqui MH, Denenberg JO, Ix JH, McClelland RL, Wassel CL, Rifkin DE, Carr JJ, Budoff MJ and Allison MA (2014): Calcium density of coronary artery plaque and risk of incident cardiovascular events. JAMA,. 311:271-278.

7. Gaibazzi N, Sicari R, Agricola E, Cioffi G, Mazzone C, Albertini L, Faden G, Molinaro S, Regazzoli D, Di Lenarda A and Faggiano $P$ (2014): Cardiac calcification at transthoracic echocardiography predicts stress echo results: a multicentre study. Int J Cardiol. 174:393395.

8. Koulaouzidis G, Nicoll $R$, MacArthur $T$, Jenkins PJ and Henein MY (2013): Coronary artery calcification correlates with the presence and severity of valve calcification. Int J Cardiol. 168:5263-5266.

9. Linefsky JP, O'Brien KD, Katz R, de Boer IH, Barasch E, Jenny NS, Siscovick DS and Kestenbaum B (2011): Association of serum phosphate levels with aortic valve sclerosis and annular calcification: the cardiovascular health study. Journal of the
American College of Cardiology, 58(3): 291297.

10. Marciano C, Galderisi $M$, Gargiulo $P$, Acampa W, D'Amore C, Esposito R, Capasso E, Savarese G, Casaretti L, Iudice FL and Esposito G (2012): Effects of type 2 diabetes mellitus on coronary microvascular function and myocardial perfusion in patients without obstructive coronary artery disease. European journal of nuclear medicine and molecular imaging, 39(7): 1199-1206.

11. Nucifora G, Schuijf JD, Van Werkhoven JM, Trines SA, Kajander S, Tops LF, Turta O, Jukema JW, Schreur JH, Heijenbrok MW and Gaemperli $O$ (2011): Relationship between obstructive coronary artery disease and abnormal stress testing in patients with paroxysmal or persistent atrial fibrillation. Int $\mathrm{J}$ Cardiovasc Imaging,. 27:777-785.

12. Panza, J.A., Holly, T.A., Asch, F.M., She, L., Pellikka, P.A., Velazquez, E.J., Lee, K.L., Borges-Neto, S., Farsky, P.S., Jones, R.H. and Berman, D.S., (2013): Inducible myocardial ischemia and outcomes in patients with coronary artery disease and left ventricular dysfunction. Journal of the American College of Cardiology, 61(18), pp.1860-1870.

13. Pressman GS, Crudu V, ParameswaranChandrika A, Romero-Corral A, Purushottam B and Figueredo VM (2011): Can total cardiac calcium predict the coronary calcium score?. International journal of cardiology, 146(2): 202-206.

14. Rajamannan NM, Evans FJ, Aikawa E, Grande-Allen KJ, Demer LL, Heistad DD, Simmons CA, Masters KS, Mathieu P, O'Brien KD and Schoen FJ (2011): Calcific aortic valve disease: not simply a degenerative process a review and agenda for research from the National Heart and Lung and Blood Institute Aortic Stenosis Working Group. Circulation, 124(16), p.1783.

15. Saha SA, Beatty AL, Mishra RK, Whooley MA and Schiller NB (2015): Usefulness of an echocardiographic composite cardiac calcium score to predict death in patients with stable coronary artery disease (from the Heart 
and Soul Study). The American journal of cardiology. 116(1):50-8.

16. Salmoirago-Blotcher E, Crawford S, Jackson E, Ockene J and Ockene I (2011): Constipation and risk of cardiovascular disease among postmenopausal women. The American Journal of Medicine, 124(8): 714723.

17. Schuijf JD, Pundziute G, Jukema JW, Lamb HJ, van der Hoeven BL, de Roos A, van der Wall EE and Bax JJ (2006): Diagnostic accuracy of 64-slice multislice computed tomography in the noninvasive evaluation of significant coronary artery disease. Am J Cardiol. 98:145-148.

18. Thanassoulis G, Campbell CY, Owens DS, Smith JG, Smith AV, Peloso GM, Kerr KF, Pechlivanis S, Budoff MJ, Harris TB and Malhotra $R$ (2013): Genetic associations with valvular calcification and aortic stenosis. N Engl J Med, 368: 503-512.

19. Thompson B and Towler DA (2012): Arterial calcification and bone physiology: role of the bone-vascular axis. Nature Reviews Endocrinology, 8(9): 529.

20. Tong L, Huang C, Ramalli A, Tortoli P, Luo J, D'hooge J, Tzemos N, Mordi I, Bishay T, Bishay $T$ and Negishi $T$ (2014): Poster session 1: Wednesday 3 December 2014, 09: 00-16: 00 Location: Poster area.
European Heart Journal-Cardiovascular Imaging, 15(suppl_2): 25-51.

21. Tousoulis D, Siasos G, Maniatis K, Oikonomou E, Vlasis K, Papavassiliou G and Stefanadis C (2012): Novel biomarkers assessing the calcium deposition in coronary artery disease. Current medicinal chemistry, 19(6), pp.901-920.

22. Weiss RM, Miller JD and Heistad DD (2013): Fibrocalcific aortic valve disease: opportunity to understand disease mechanisms using mouse models. Circulation research, 113(2), pp.209-222.

23. Yahagi K, Kolodgie FD, Otsuka F, Finn AV, Davis HR, Joner $M$ and Virmani $R$ (2016): Pathophysiology of native coronary, vein graft, and in-stent atherosclerosis. Nature Reviews Cardiology, 13(2), p.79.

24. Youssef G, Kalia N, Darabian $S$ and Budoff MJ (2013): Coronary calcium: new insights, recent data, and clinical role. Current cardiology reports, 15(1): 325. 


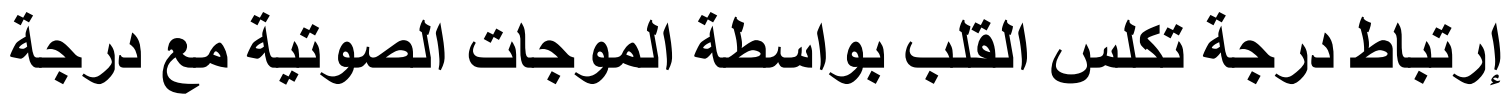

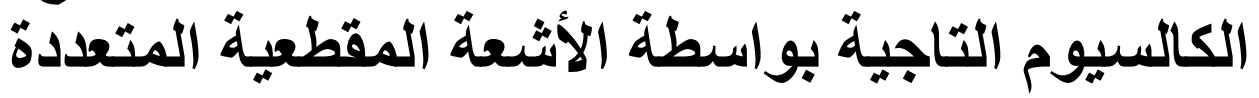

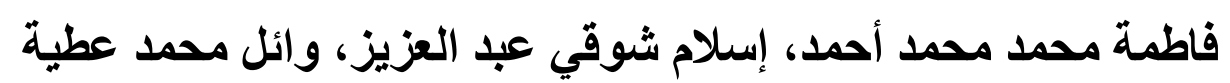

قسم أمراض القلب بكلية الطب، جامعة الأزهر (القاهرة)

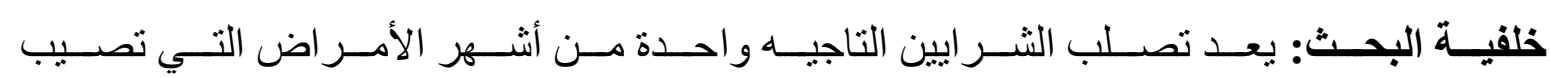

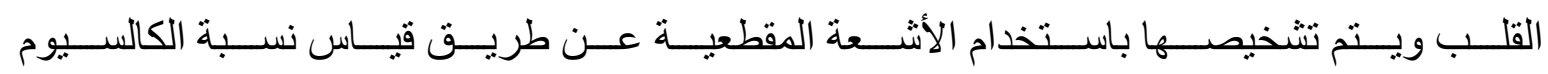

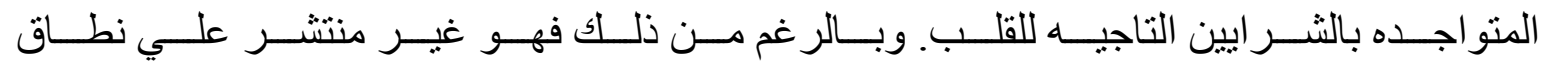

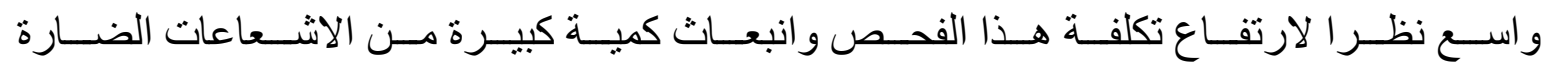

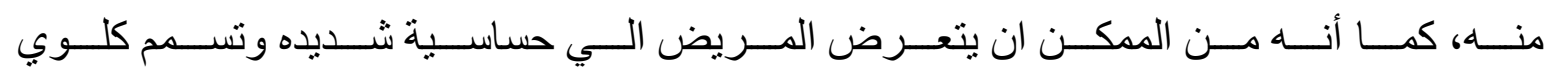

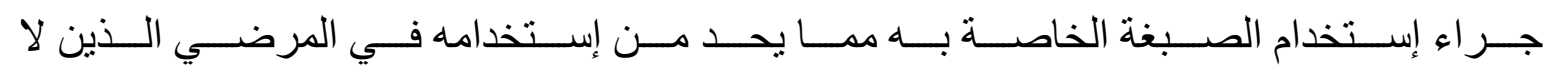
يعانون من أية أعر اض بالقلب.

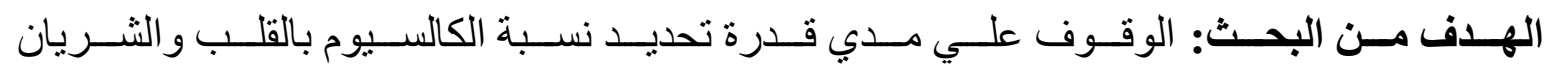

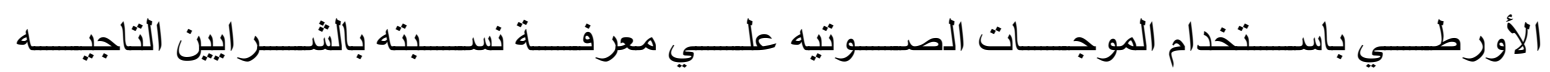

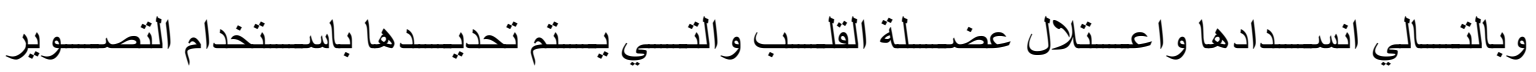
المقطعي المحوسب.

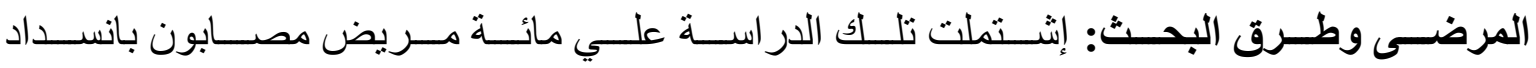

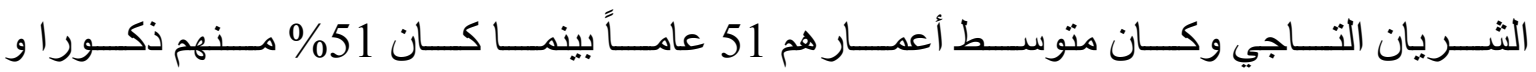

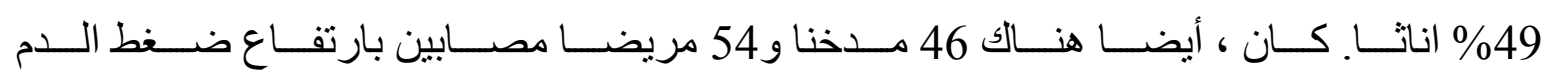

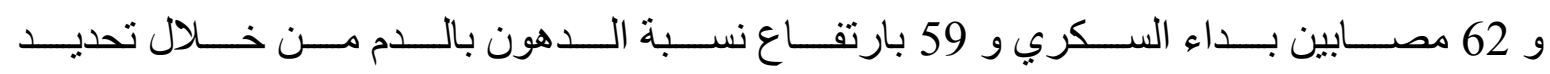

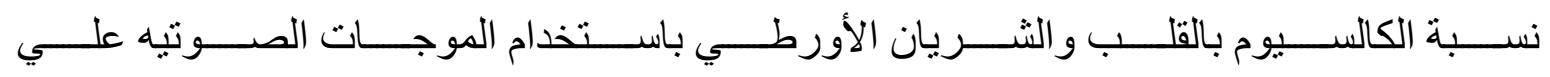

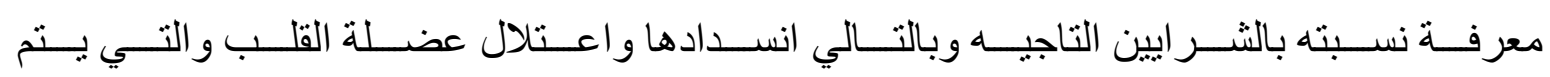
تحديدها باستخدام التصوير المقطعي المحوسب. بالبئ.

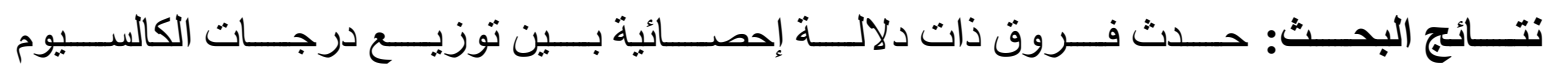

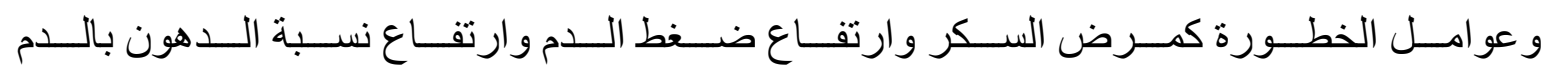

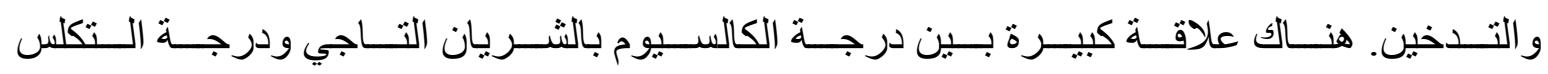

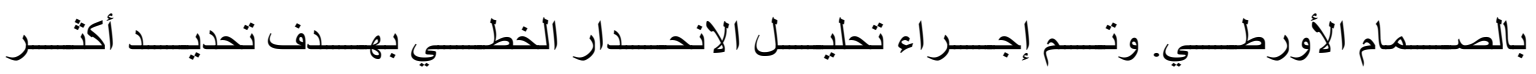


CORRELATION OF ECHO CARDIAC CALCIFICATION SCORE WITH... ${ }^{1427}$

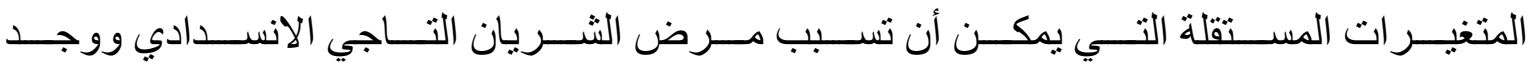

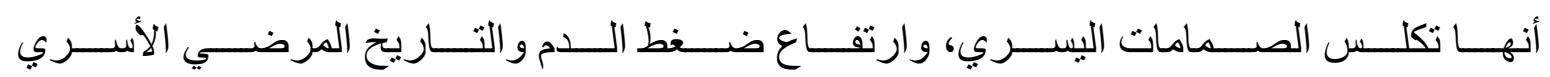

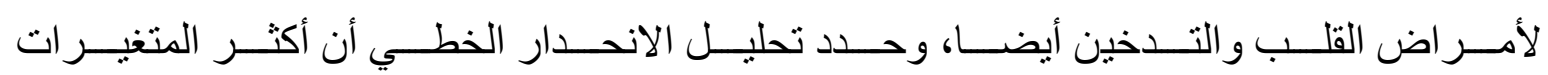

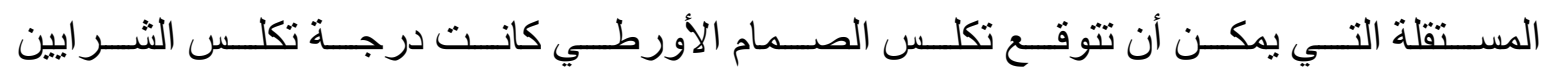

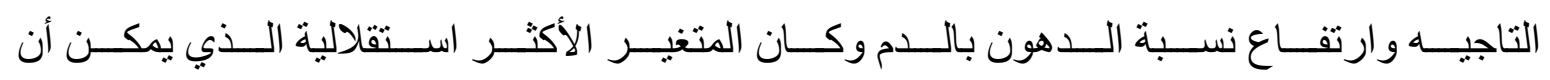
يتنبأ بمرض الثريان التاجي الانسدادي هو وجود تكلس بالثريان التاجي.

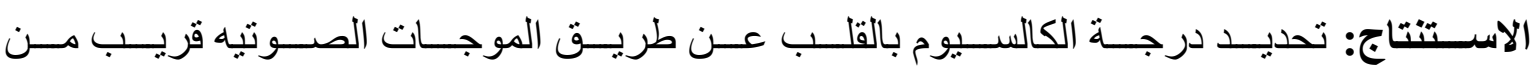

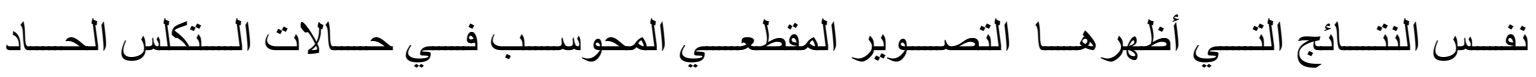

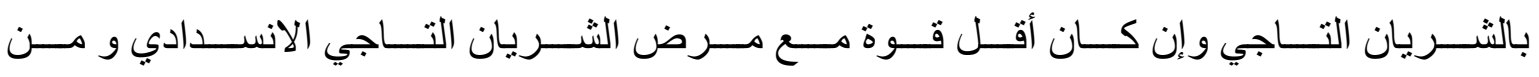

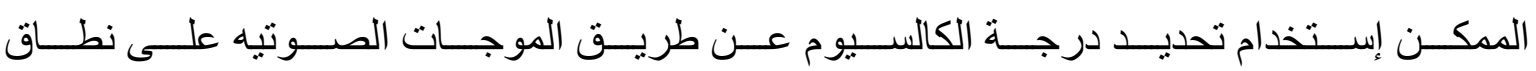

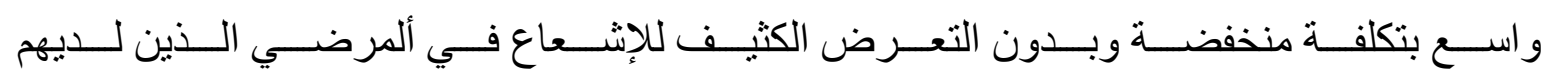

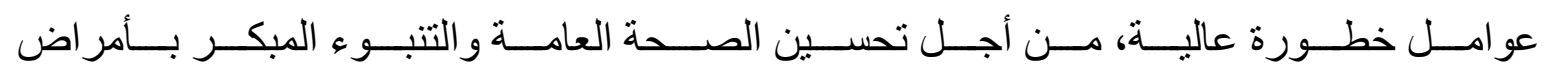
القلب ومن ثم تنافيها. 